\title{
Mathematical Model of Proportional Spool Valve WITH IMPROVED TEMPERATURE DEPENDENCE
}

\author{
Petr Chernus*, Valery Sharovatov \& Pavel Chernus
}
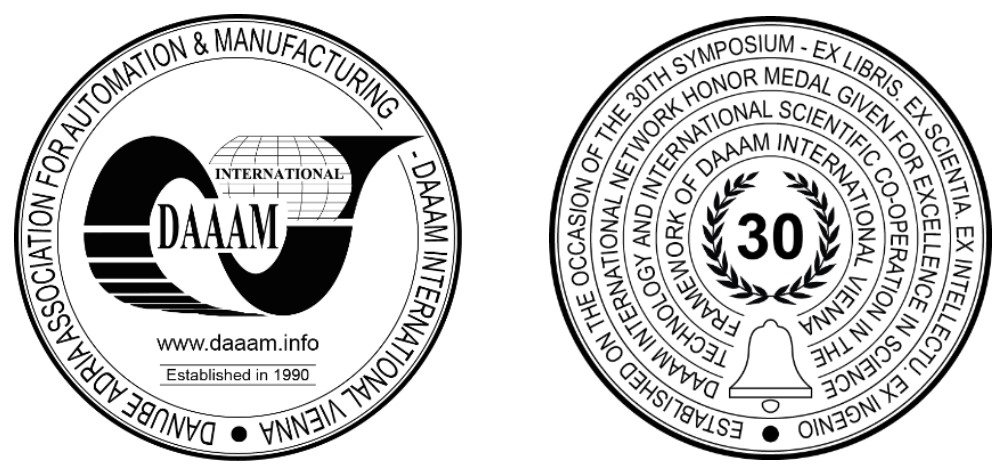

This Publication has to be referred as: Chernus, P[etr]; Sharovatov, V[alery] \& Chernus, P[avel] (2020). Mathematical Model of Proportional Spool Valve with Improved Temperature Dependence, Proceedings of the 31st DAAAM International Symposium, pp.0218-0223, B. Katalinic (Ed.), Published by DAAAM International, ISBN 9783-902734-29-7, ISSN 1726-9679, Vienna, Austria DOI: $10.2507 / 31$ st.daaam.proceedings.029

\begin{abstract}
This paper presents an improved mathematical model of proportional spool valve flow characteristics. Emphasis is made on improving of variational model of average values of gas flow temperature in different sections of the valve. This improvement makes it possible to get more accurate mass flow rate value, especially on subcritical flow, what is important for use of different types of membranate and elastic elements. The model is verified with gas flow mathematical modelling.
\end{abstract}

Keywords: mathematical model; proportional valve; gas flow; flow characteristics; pressure ratio.

\section{Introduction}

Non-standard elements such as shell and membrane elements of various action types, for example, pneumatic artificial muscles, bellow cylinders, and elastic Bourdon tubes are increasingly being used as perspective actuators in various tasks of robotics and automation. The latter have significant potential for their use as a small displacement actuator. Their use is especially important in those areas of industry where it is required to observe the absence of electric and magnetic fields. However, to control the movement of such an element, it is necessary to know not only its mathematical model, but also the model of the pneumatic valve.

To date, there are a number of papers, describing the development of mathematical models of pneumatic artificial muscles [1], [2], [3], [4], [5], [6], [7], [8], [9] and bellow cylinders [10], [11], [12], as well as Bourdon tubes [13]. Unfortunately, in most of these papers the actuators are described as separate elements, or use a simplified model of the pneumatic valve. It should be noted that there are also works devoted to the study of proportional pressure regulators [14]. Pneumatic proportional spool valve (fig. 1) presented in this paper is used for fast and precise gas flow control. In combination with an external position and pressure sensors and controllers, a precise and fast-acting pneumatic system could be created. 


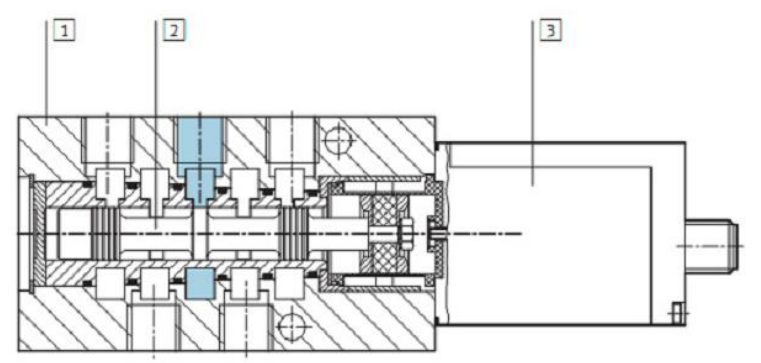

Fig. 1. Proportional pneumatic valve. 1 - housing, 2 - valve spool, 3 - housing for electronics.

In this paper is presented a development of improved mathematical model of the proportional valve, based on the geometrical dimensions of the valve Festo MPYE-5-1/8LF-010-B. Spool dynamics and electro-magnetic part of the valve are described by authors in previous papers [15], [16]. Although an improved model was given, which was taking into consideration the change in the average values of the temperature of the gas flow during its flow through the pneumatic valve, it rather accurately describes the processes with a relatively small pressure ratio at the inlet and outlet of the pneumatic valve. When pressure ration is close to one, inaccuracy can reach 6-10\%. When as an actuator is used pneumatic artificial muscle or bellow cylinder having relatively large inner volume, this model inaccuracy will not influence significantly on system, especially since the main operating mode of the pneumatic valve in this case is associated with a small pressure ratio. When using Bourdon tubes with small internal volume, the main operating mode of the valve will be associated with pressure ratio close to one. For this reason it is necessary to adjust mathematical model parameters.

\section{Description of air flow through the valve}

Pneumatic valve is usually mathematically described as a throttle, mass flow rate through which one can calculate [17]:

$$
\begin{aligned}
& G=G^{*} \cdot f\left(\frac{p_{b}}{p_{a}}\right), \\
& G^{*}=0.039 \cdot \mu \cdot b \frac{p_{a}}{\sqrt{\theta_{a}}} x_{v} \\
& f\left(\frac{p_{b}}{p_{a}}\right)=\left\{\begin{array}{c}
2 \sqrt{\left(1-\frac{p_{b}}{p_{a}}\right) \frac{p_{b}}{p_{a}}}, \text { when } \frac{p_{b}}{p_{a}}>0,528 \\
1, \text { when } \frac{p_{b}}{p_{a}} \leq 0,528
\end{array}\right.
\end{aligned}
$$

where $\mathrm{G}^{*}$ - means critical mass flow rate $(\mathrm{Ma} \approx 1)$;

$p_{a}$ - means constant input pressure;

$p_{b}$ - means constant output pressure;

$\mu$ - means flow coefficient of throttle aperture;

$b$ - means aperture width;

$\theta_{a}$ - means input gas temperature.

Since the pneumatic spool valve is a complex structure with 2 throttling windows and a narrow channel between them, which increases local resistance, the following system of equations can describe it [16]:

$$
\left\{\begin{array}{l}
G_{1}=0.039 \cdot \mu_{1} \cdot b \frac{p_{i}}{\sqrt{\theta_{i}}} f\left(\frac{p_{1}}{p_{i}}\right) x_{3}, \\
G_{2}=0.039 \cdot \mu_{2} \cdot b \frac{p_{2}}{\sqrt{\theta_{2}}} f\left(\frac{p_{o}}{p_{2}}\right) x_{\mathrm{M}}, \\
\triangle p=p_{1}-p_{2}, \\
G_{1}=G_{2}=G, \\
\triangle p=\xi \frac{v^{2}}{2} \rho, \\
v=\frac{G}{\rho A_{c h}}
\end{array}\right.
$$

where $G_{l}$ and $G_{2}$ - means mass flow rates through first and second throttle apertures; $A_{c h}$ - means cross sectional area of the channel, in this case it is a ring.

Valve inner space longitudinal section is shown in Figure 2. With numbers 1 and 2 are marked surfaces of air flow parameters (temperature, pressure, density, etc.) after and before corresponding throttle aperture. Then the solution of equation system (2) is the following: 


$$
\begin{aligned}
& G=0,039 \cdot \mu_{1} \cdot b \frac{p_{i}}{\sqrt{\theta_{i}}} f\left(\frac{p_{1}}{p_{i}}\right) x, \\
& p_{1}=\frac{1}{2}\left(\begin{array}{l}
p_{i}-\left(\frac{\mu_{2}}{\mu_{1}}\right)^{2}\left(\frac{x_{m}}{x}\right)^{2} \frac{\theta_{i}}{\theta_{2}}\left(1+69 \xi \frac{\theta_{1}}{\theta_{i}} \mu_{1}^{2} \frac{b^{2} x^{2}}{A_{c h}^{2}}\right) p_{o}+ \\
+\sqrt{\left(p_{i}-\left(\frac{\mu_{2}}{\mu_{1}}\right)^{2}\left(\frac{x_{m}}{x}\right)^{2} \frac{\theta_{i}}{\theta_{2}}\left(1+69 \xi \frac{\theta_{1}}{\theta_{i}} \mu_{1}^{2} \frac{b^{2} x^{2}}{A_{c h}^{2}}\right) p_{o}\right)^{2}} \\
+4\left(\frac{\mu_{2}}{\mu_{1}}\right)^{2}\left(\frac{x_{m}}{x}\right)^{2} \frac{\theta_{i}}{\theta_{2}}\left(p_{o}+69 \xi \frac{\theta_{1}}{\theta_{i}} \mu_{1}^{2} \frac{b^{2} x^{2}}{A_{c h}^{2}} p_{i}\right) p_{o}
\end{array}\right)
\end{aligned}
$$

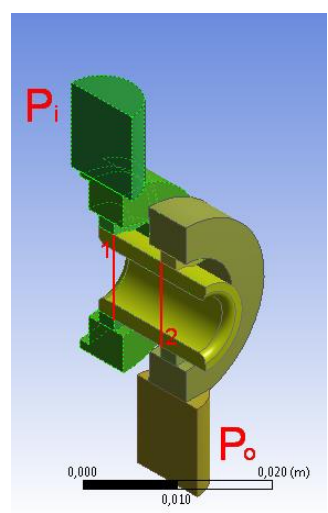

Fig. 2. Valve inner space longitudinal section

\section{Evaluation of air flow temperature}

The main difficulty in determining the temperature value lies in the fact that the Navier-Stokes equation must be solved to get accurate problem solution. Use of finite elements numerical methods can give relatively accurate solution, but it demands large amount of processing power and time. On the other hand, since the process of gas flow through the pneumatic valve is fast enough, then one can use the equations describing the adiabatic process. In this case it is necessary to know pressure values $p_{1}$ and $p_{2}$, which are unknown. Another difficulty lies in the fact that in the crosssection of the channel there is a rather strong inhomogeneity of the flow parameters because of a pronounced jet formed due to the passage of the gas flow through the throttling window. On Figure 3 is depicted the distribution of the gas flow temperature at different values of the inlet and outlet pressures and at various degrees of opening of the pneumatic valve, and in the case corresponding to Fig. 3a), there is a critical gas flow rate through the first throttle window.
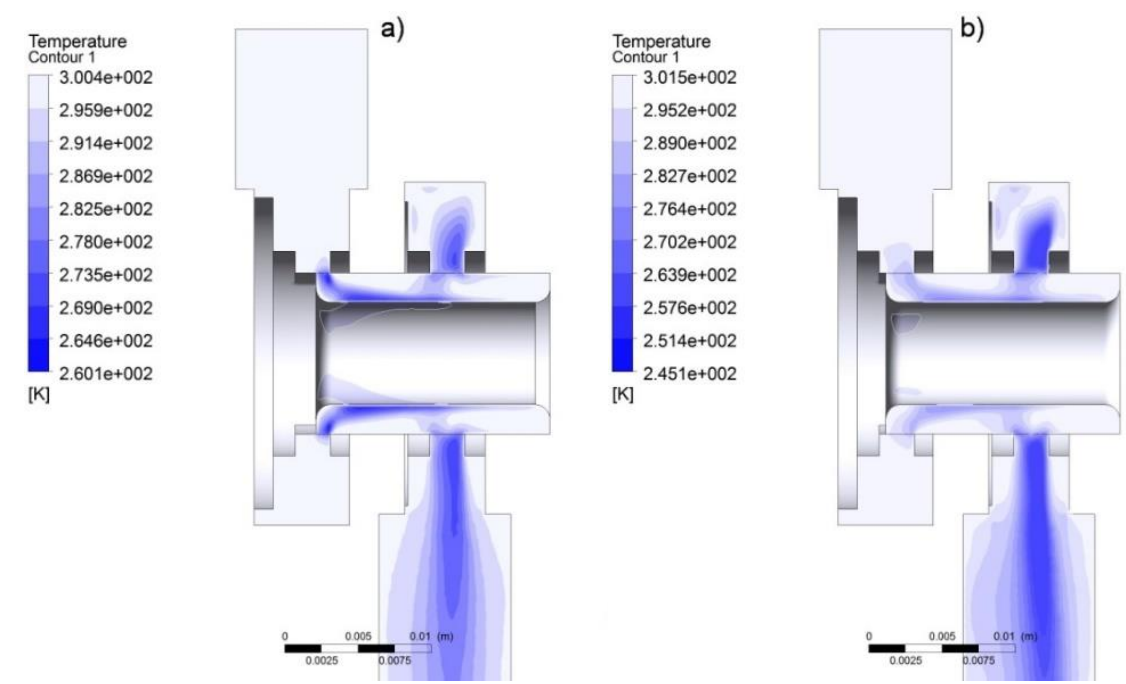

Fig. 3. Air flow temperature. a) valve open on $40 \%, p_{i}=5$ bar, $p_{o}=1 \mathrm{bar}$; b) valve open on $80 \%, p_{i}=5$ bar, $p_{o}=1$ bar;

By modelling results was found out that average value of temperature $\theta_{l}$ mostly depends on input/output pressure ratio. This is due to the fact that when the pneumatic valve is opened, a gas jet is formed, in which the temperature decreases due to a significant increase in the flow velocity. This relation is not highly non-linear, so temperature value $\theta_{1}$ could be calculated with a help of the following empirical equation: 


$$
\theta_{1}=\theta_{i}\left(\alpha-\beta\left(1-\frac{p_{o}}{p_{i}}\right)^{1.4}\right)
$$

Such form of the equation is proposed because of adiabatic flow mode. By calculating the coefficients using the least squares method, it is possible to get the following result:

$$
\theta_{1}=\theta_{i}\left(0.994-0.097\left(1-\frac{p_{o}}{p_{i}}\right)^{1.4}\right)
$$

Figure 4 shows the graphs of approximation of the averaged temperature value $\theta_{l}$ by the given expression for different values of the inlet and outlet pressures.

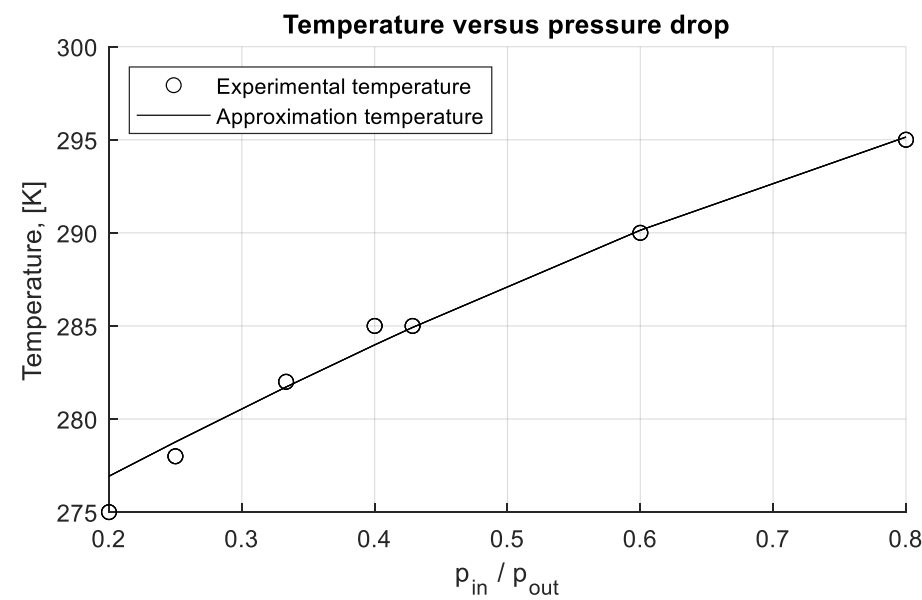

Fig. 4. Approximation of the averaged temperature value $\theta_{1}$

Mean temperature value $\theta_{2}$ depends not only on input/output pressure ratio, but also on valve opening. There was developed the following equation to calculate temperature $\theta_{2}$ value using least squares method:

$$
\theta_{2}=\theta_{i}-75\left(1-\frac{p_{o}}{p_{i}}\right)^{1.4}\left(\frac{x}{x_{m}}\right)^{1.5}
$$

On Figure 5 is depicted the graphs of approximation of the averaged temperature value $\theta_{2}$ by the given expression for different values of the inlet and outlet pressures and valve opening.

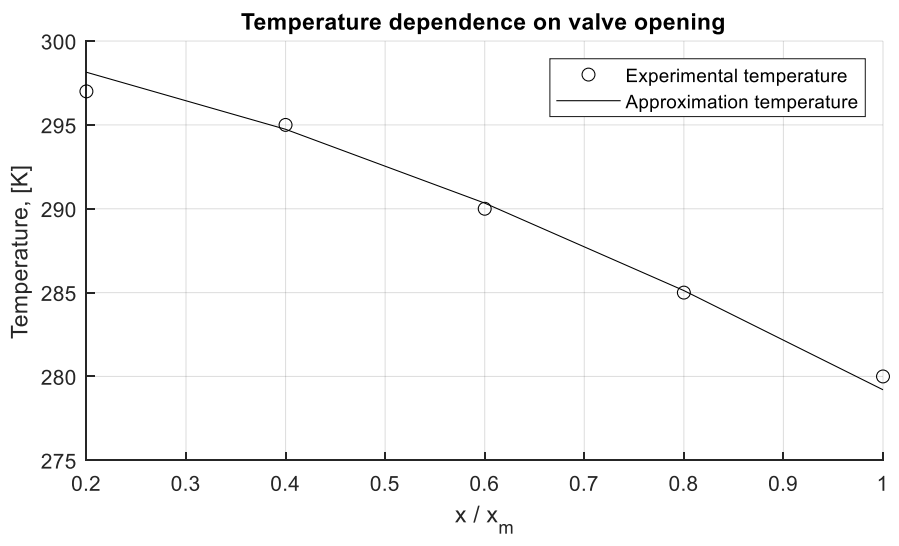

Fig. 5. Approximation of the averaged temperature value $\theta_{2}$

\section{Results}

In previous sections were evaluated values of average flow temperature $\theta_{1}$ and $\theta_{2}$ with equations (5)-(6). All other parameters and constants from equation (3) were found by authors in previous research [16], [17]. Values of mass flow rate through the valve received by modelling results and with an equation (3) with different values of input and output pressure are shown in figure 6. 

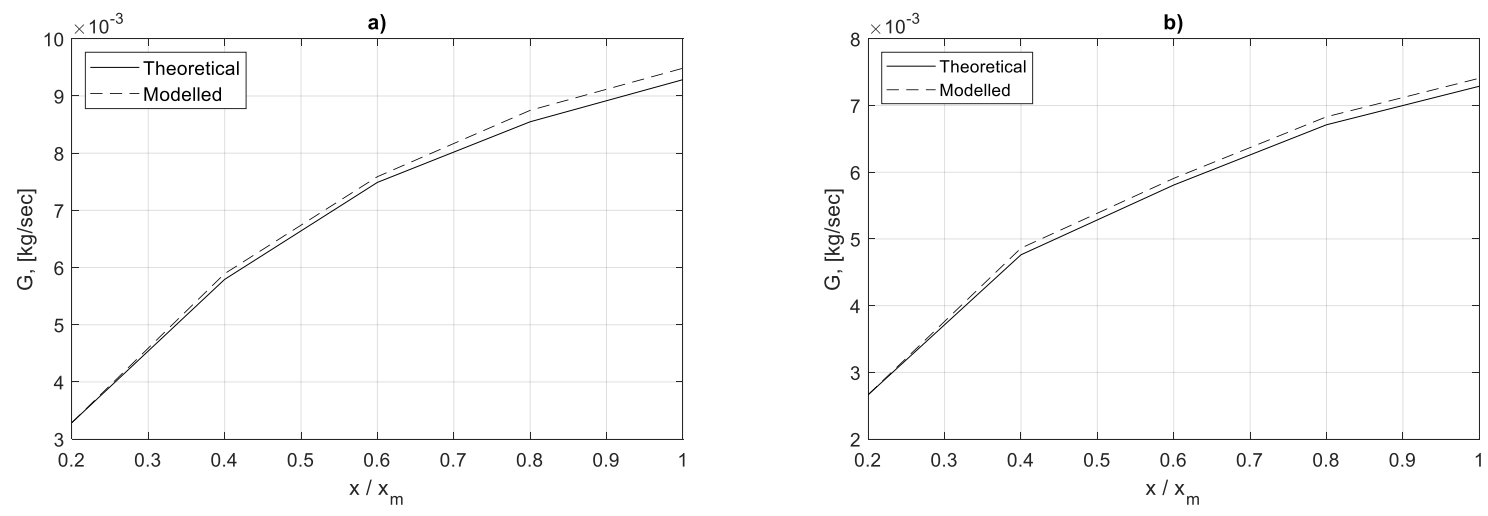

Fig. 6. Mass flow rate: a) when $p_{i}=5$ bar, $p_{o}=1$ bar; b) when $p_{i}=5$ bar, $p_{o}=3$ bar

Comparison of simulation and theoretical calculation shows us that the model works accurate (error is less than 6\%), especially when pressure ratio is close to one.

As a result, was developed improved mathematical model of a proportional pneumatic spool valve. The model with adjusted expressions for averaged values of temperatures gives accurate values of mass flow rate, especially when pressure ratio is close to one. The main advantage of this model is that the model based not on experimental data of particular valve, but on general gas dynamics theory. Consequently, this model could be used for a class of pneumatic valves. Finally use of developed improved mathematical model of valve flow rate together with membranate actuators and Bourdon tubes models makes possible a design of fast and precise robotics and automation systems.

\section{Conclusion}

Improved mathematical model of flow rate of proportional pneumatic spool valve is presented in this paper. The main reason of creation of such model was consideration of air flow temperature average values variations to decrease model error, especially when input/output pressure ratio is close to value of one. Emphasis is made on developing of accurate easy-to-calculate universal mathematical model which could be used for a class of pneumatic valves. Due to high degree of heterogeneity of the temperature value in cross-section of the inner channel is presented non-linear equation, which is optimized with a help of least squares method.

The logical next step would be verification of received results by experimental data. Further research will be focused on verifying received results with help of experiment.

\section{References}

[1] G. Andrikopoulos, G. Nikolakopoulos, S. Manesis, "A survey on applications of pneumatic artificial muscles", Proceedings 19th Mediterranean Conference on Control and Automation, pp. 1439-1446, 2011.

[2] Daerden, F., Lefeber, D.: Pneumatic Artificial Muscles: actuators for robotics and automation. European Journal of Mechanical and Environmental Engineering. Citeseer, 2002, issue 1, vol. 47, pp. 11-21.

[3] Loshitskiy, P.A., Sharovatov, V.T., Mathematical model of dual-acting force mambranate rodeless pneumocylinder, Mechatronics, Automation, Control, Moscow, 2012, №4, pp. 24-30.

[4] K. C. Wickramatunge, T. Leephakpreeda, Empirical modeling of dynamic behaviors of pneumatic artificial muscle actuators, ISA Transactions, Vol. 52, Issue 6, 2013, pp. 825-834.

[5] S. Ganguly, A. Garg, A. Pasricha, S.K. Dwivedy, Control of pneumatic artificial muscle system through experimental modelling, Mechatronics, Vol. 22, Issue 8, 2012, pp. 1135-1147.

[6] Li, S., Vogt, D. M., Rus, D., and Wood, R. J. (2017). Fluid-driven origami-inspired artificial muscles. Proc. Natl. Acad. Sci. U.S.A. 114, 13132-13137. doi: 10.1073/pnas.1713450114

[7] Veale, A.J., Xie, S.Q., and Anderson, I.A. (2016). Modeling the Peano fluidic muscle and the effects of its material properties on its static and dynamic behavior. Smart Mater. Struct. 25, 065014.

[8] William Scaff, Oswaldo Horikawa, Marcos de Sales Guerra Tsuzuki, Pneumatic Artificial Muscle Optimal Control with Simulated Annealing, 10th IFAC Symposium on Biological and Medical Systems BMS 2018, Volume 51, Issue 27, pp. 1-424 (2018)

[9] Sharovatov V., Chernus Pav., Chernus P. Silovie obolochkovie element: istorichskaja spravka, staticheskie matematicheskie modeli, primenenie (obzor) (Power shell elements: historical background, static mathematical models, application (overview)) / "Mekhatronica, Avtomatizatsiya, Upravlenie", ISSN 1684-6427, vol. 10, 2018, pp.642-657.

[10] V. Sharovatov, P. Chernus, Mathematical Model of a Strength Part of a Push Type Single-Acting Rodless Pneumatic Cylinder, Mechatronics, Automation, Control, №9, 2014, pp. 30-36. 
[11] Chernus Pavel, Sharovatov Valery. Dynamic Mathematical Model of Two-way Bellow Actuator. // ProcediaEngineering, Vol. 100, 2015, pp. 1040-1045.

[12] Chernus, P[avel]; Sharovatov, V[alery] \& Chernus, P[etr] (2016). Modelling of Two-Way Bellow Actuator Positioning, Proceedings of the 26th DAAAM International Symposium, pp.0620-0625

[13] V.A. Vasin, E.N. Ivashov, S.V. Stepanchikov, Calculations lead and functional units of modern vacuum technology unit complexes in static and dymanic models, Nonlinear World, Vol.10, No. 1, 2012

[14] Varga, Z., Honkola, P.-K., Mathematical model of pneumatic proportional valve, Journal of applied science in thermodynamics and fluid mechanics Vol.1, No. 1/2012.

[15] P.P. Chernus, V.T. Sharovatov, Accounting for compressed gas properties in the mathematical model of a spool valve // Proceedings of higher educational institutions. Machine building, №12, 2014, pp. 22-29

[16] Petr Chernus, Valery Sharovatov, Consideration of influence of peculiarities of compressed gas on mathematical model parameters of spool valve. // Procedia Engineering, Vol. 100, 2015, pp. 1046-1054.

[17] Chernus, P[etr]; Sharovatav, V[alery] \& Chernus, P[avel] (2016). Mathematical Model of Proportional Spool Valve, Proceedings of the 26th DAAAM International Symposium, pp.0626-0632 